\title{
GDP Falls as MBA Rises?
}

\author{
T. N. Cummins \\ EconomicGPS, Aurora, USA \\ Email: thadncs@gmail.com
}

Received August 15, 2013; revised September 15, 2013; accepted September 22, 2013

Copyright (C) 2013 T. N. Cummins. This is an open access article distributed under the Creative Commons Attribution License, which permits unrestricted use, distribution, and reproduction in any medium, provided the original work is properly cited.

\begin{abstract}
By charting US GDP growth rates beginning from 1953 through the Bush administration of 2008, an inverted "V" pattern appears with 1980 as an approximate pivot point. The observable upward trend of the US economy after WWII and before 1980 coincides with more active public domestic budgets when compared with budgets after 1980. Political discourse in the late 20th century suggests an economic policy shift away from public investments toward private sector interests which may have contributed to structural changes in the US economy. After charting pre- and post-1980 US quarterly GDP data, a fifty-six-year naturally occurring quasi-experimental design [1] displays two periods of different economic outcomes. By exploring a plausible contributor to the change in economic trend data using applied math, concerned parties may begin to map out the unknown unknowns of economic performance. This paper uses the best linear unbiased estimator of Gauss and Markov to quantify economic rates of growth in each period. Pearson's correlation coefficient attempts to characterize mathematically the impact of systemic political change on US economic performance. Finally, a Chow test confirms structural change is afoot. With the help of statistical analysis, this paper explores if the increase in US business majors since 1980 has or has not delivered ever improving US GDP growth from 1980-2008. This work is important as the economic health of a nation over the long run allows nations to protect and provide for their citizens.
\end{abstract}

Keywords: Economic Growth; GDP; Correlation Coefficient; Quasi-Experimental Design; Economic Policy; Chow Test; Management; Mental Models; Business History; National Security; Public Goods; MBA; Structural Change

\section{Introduction}

The United States Gross Domestic Product (GDP) represents the market value of all recognized goods and services produced by the United States in a calendar year. GDP "growth rate" measures the rate of change in the summation of GDP year to year as an outcome measure of US economic performance. The report first compares US GDP growth rates between two comparable economic periods and then examines covariance with a potential independent variable. In the end, the report finds two economic periods have experienced statistically significant structural change. Has the rising preference for business degrees in US society after 1980 contributed to economic change? Few will likely be surprised to learn that US graduation rates of business majors reaches 500,000 in the 2009-2010 academic years [2].

\section{Signal Discovery in Statistical Noise}

Calculation of the US GDP uses census data compiled every five years with progressive elaboration to include household surveys during interim years [3]. A cross section of comparison follows (Table 1).

US GDP measurements have known inconsistencies. For example, GDP calculated annually does not always match quarterly totals. Data variances emerge, develop and consolidate over time reflecting ongoing data collection and reassessments by statistical professionals. The difficult work of understanding the unknown unknowns of what impacts GDP growth over time contends with the "statistical noise" of collection and re-calculations. A complex social phenomenon like cultural decision making over time is therefore approached with the best linear

Table 1. Statistical Brief [4].

\begin{tabular}{ccc}
\hline Years & & \\
\hline & Mean GDP & Highest Lowest Variance \\
\hline $1953-1980$ & 3.53 & LBJ 6.2Ike (1.0) 7.2 \\
$1981-2008$ & 2.79 & Reagan 5.2Bush II (0.5) 4.7 \\
\hline
\end{tabular}


unbiased estimator sometimes called best linear unbiased predictor. This study is not trying to predict but rather characterize so the best linear unbiased estimator or BLUE will be used to describe covariance between US GDP growth and growing preference for MBA degrees in public and private organizations since 1980. Despite statistical noise, US GDP reports influence business decision making and when taken in broad view over decades the US GDP informs our understanding of policy impacts with the luxury of hindsight.

The inverted "V" of GDP is not visible at first glance. Lost beneath a semi-rhythmic pattern of up and down variance over fifty-six years there appears to be no difference over time (Figure 1). However, after applying a magnitude of four to US BEA data the pattern below appears. Like a microscope, patterns become more visible after magnification. Patterns invite analysis. So applied math is needed to test. In this case Pearson's R and a Chow test is needed to confirm what the eye can see.

Mathematical tools keep us honest. To that end a NULL hypothesis proposing private sector management preference in society improves GDP growth rates over time, is tested. If the relationship can be shown between MBA growth and GDP growth the assumption that more business minded professionals improve economic performance has basis. On the other hand, the alternative hypothesis will be tested as well.

\section{A Rare Quasi-Experimental Design}

The up and down trend of US GDP growth rates before and after 1980 provides a living experimental design useful for social and business research. The management preference for business degreed professionals as documented by the Graduate Management Admissions Council supports other report findings of MBA graduation rates including 100,000 [5] in 2008 increasing to 160,000 in 2011 [6]. When considering other factors constraining economic growth both economic periods experienced equal proportions of war and economic turmoil (Table 2).

\subsection{Economic Structural Change}

While the rise of the MBA as the preferred management model [7] in society remains nominal until 1980 with a growth rate of under 7\% [8] the MBA graduation growth rate climbs to over $20 \%$ by 1990 [9]. Pundits argue the structural changes in the US economy since 1980 are due to globalization, China, the Iraq war, bank failures and a lack of skilled workers. Another plausible hypothesis may be the systemic shift in US management preferences best articulated in the rise of the MBA degree since 1980 Given the history of these two periods neither period warrants special consideration for the impacts of war or economic turmoil. We must look elsewhere.

\subsection{MBA Part of Overall Cultural Shift}

A shift in US political culture captured by the management preference for the MBA happened at the same time as market deregulation. In addition pro-business tax benefits and muted domestic spending contributed to post-1980

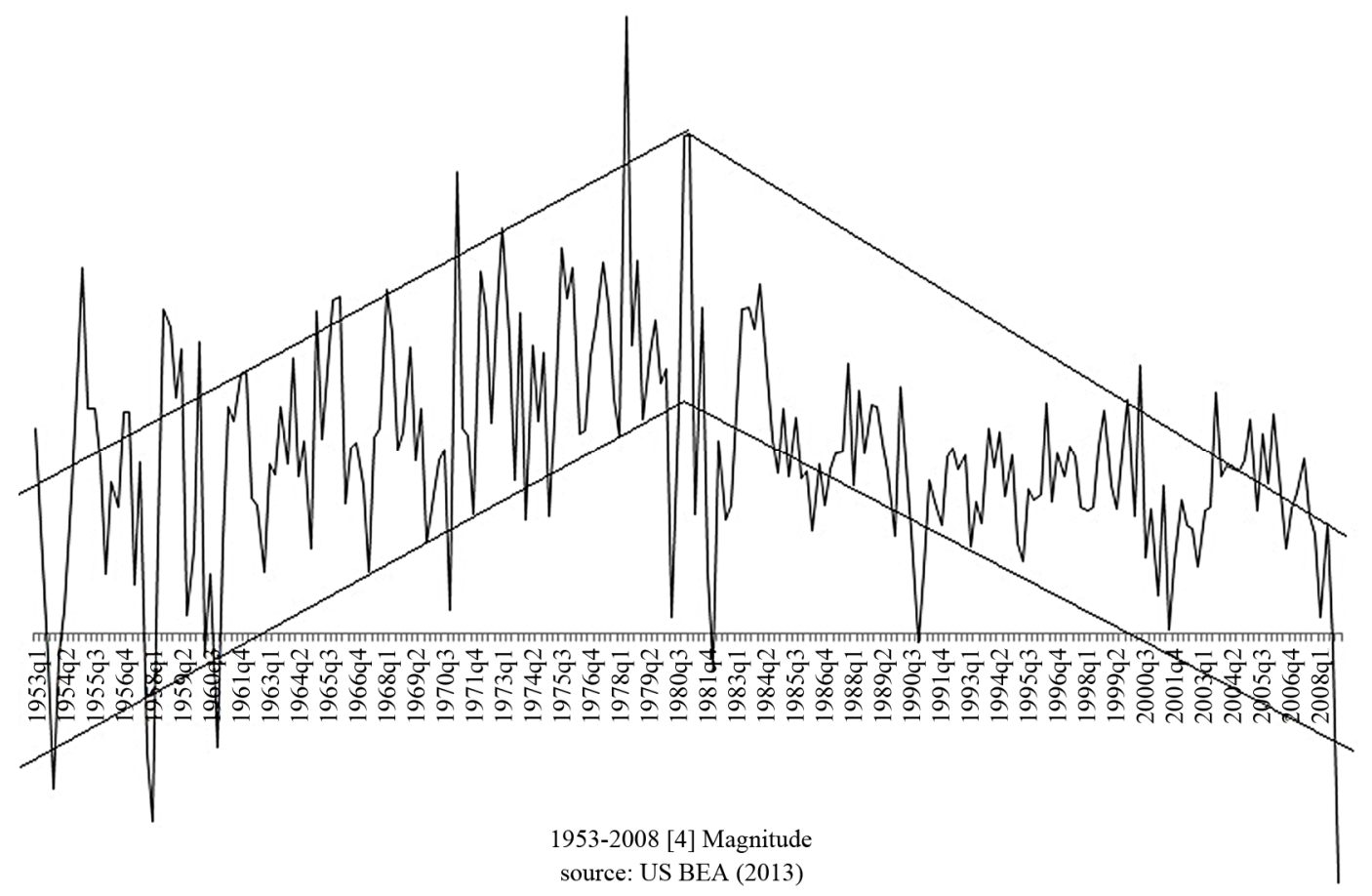

Figure 1. Inverted "V" of GDP only viewable after magnification. 
economic structural controls. The MBA degree has no math for "public goods". As such, a count of business majors quantifies growing social preference for a way of

Table 2. Cross panel of economic and military constraints.

\begin{tabular}{ccc}
\hline \multirow{2}{*}{ Years } & \multicolumn{3}{c}{ War } & Economic Turmoil \\
\cline { 2 - 3 } 1953-1980 & Korea, Vietnam, Cold & Floating USD, Two Oil Crises \\
1981-2008 & Kuwait, Iraq, Afghanistan & Generational Banking Failures \\
\hline
\end{tabular}

making economic decisions. Annual graduation rates capture a measurable social variable over time. The quailties and quantity of the MBA thought model propagating throughout public and private markets in the late 20th and early 21 st centuries may have had an impact on the economy and US political culture (Figure 2). Discerning between statistical noise and signal requires a simple and direct approach. A best linear unbiased estimator is used to determine if there is a slope, and if so, resulting math helps characterize population dynamics (Figures 3 and 4).

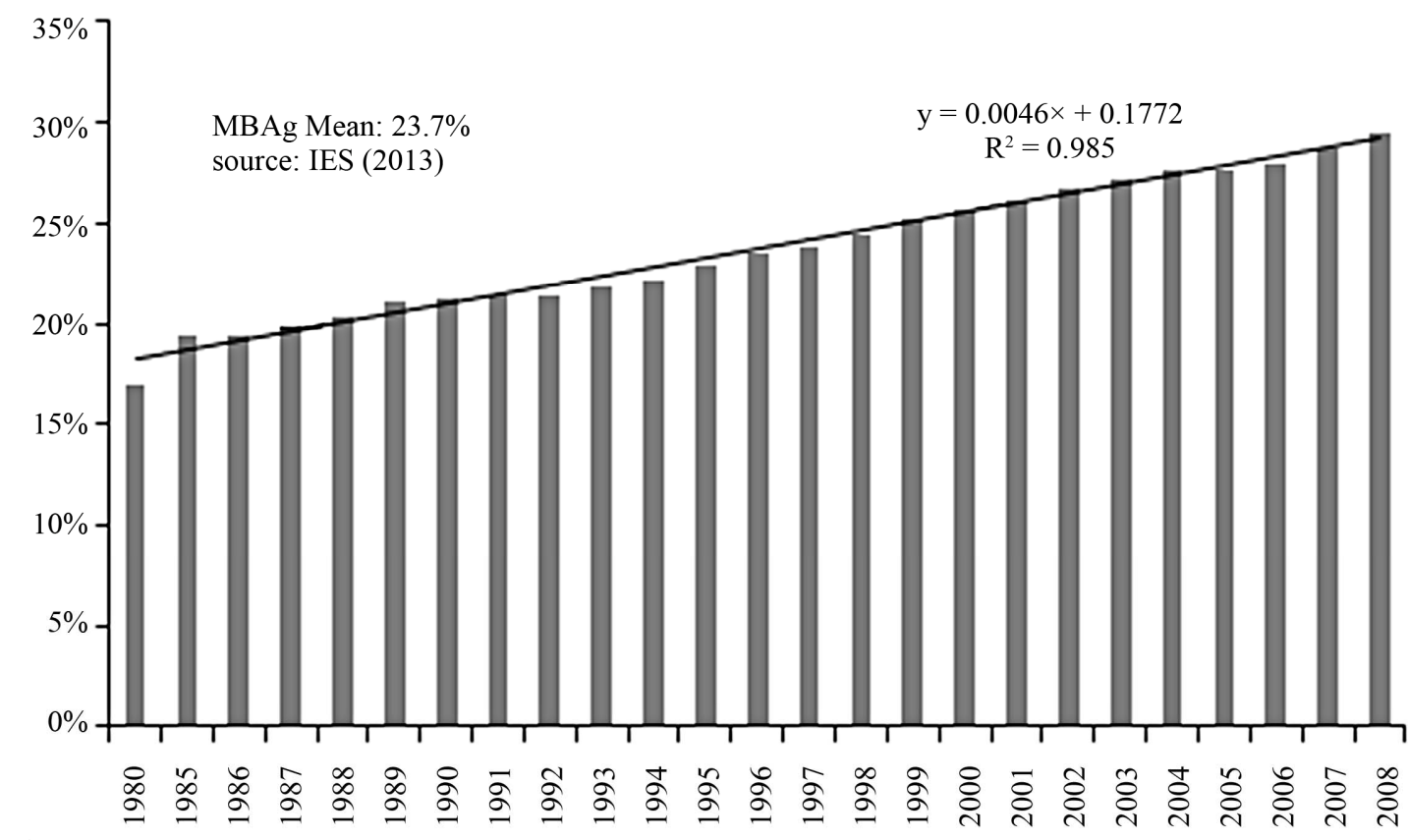

"BLUE MBAg 1981-2008 [10].

Figure 2. “MBAg-MBA Preference Growth”.

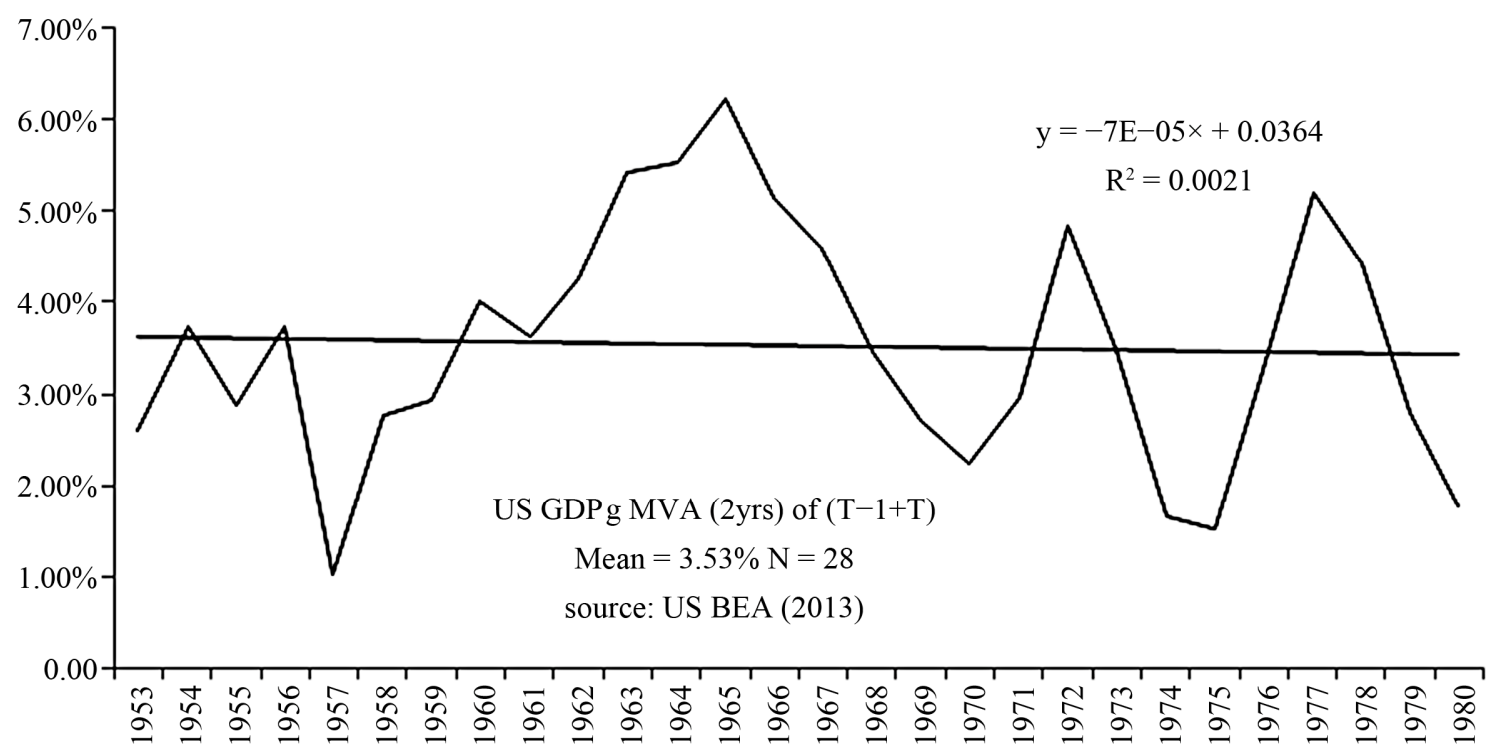

"BLUE US GDPg 1953-1980 [11].

Figure 3. "Eisenhower-Carter Economy". 


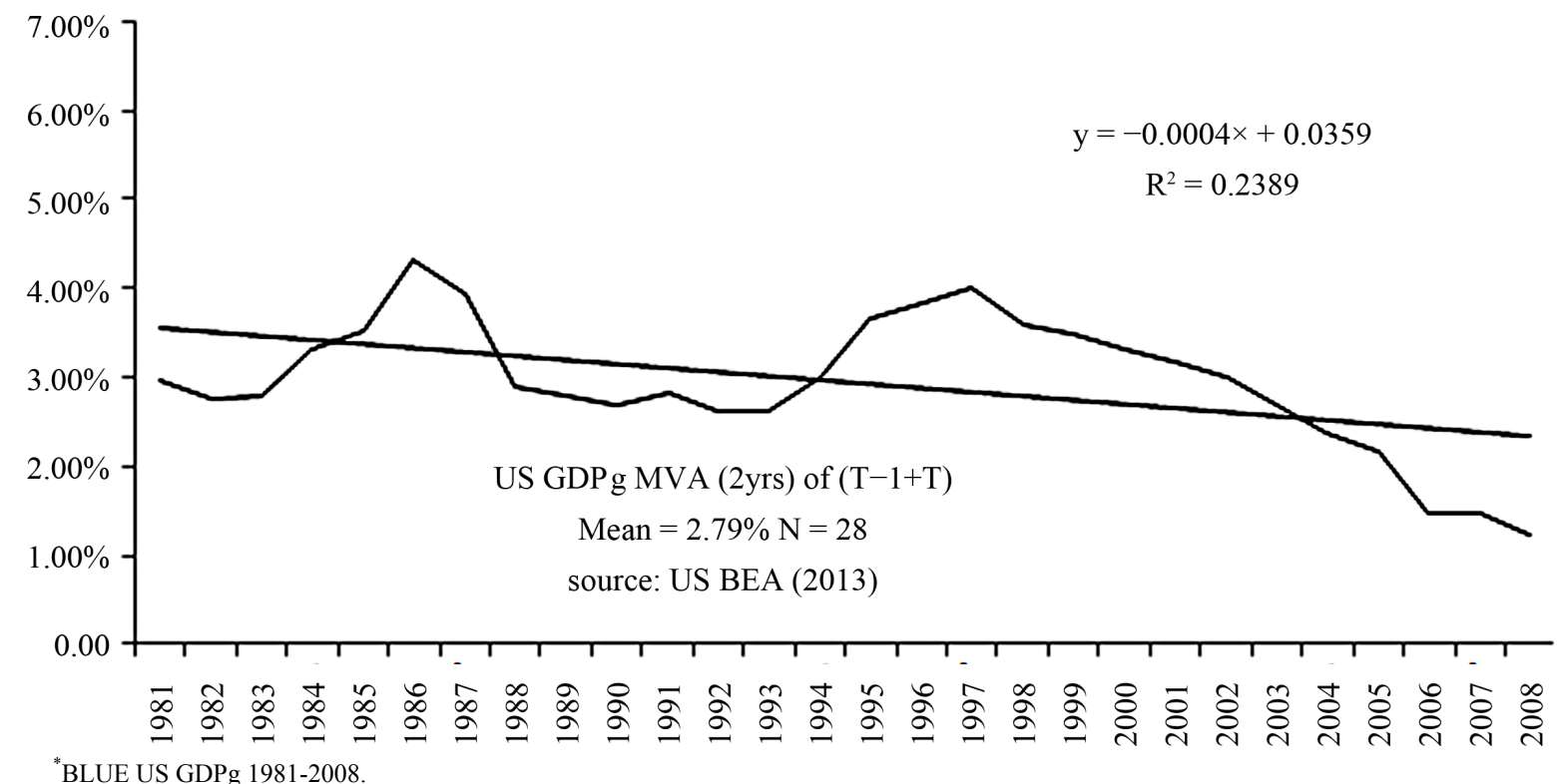

Figure 4. "Reagan-Bush Economy”.

\section{Best Linear Unbiased Estimators}

Pearson's Correlation Coefficient (Equation (1)) has a solid scientific history for analysis of relationship between linear variables when working with noisy data.

\section{Applied Math}

\subsection{Equation (1)}

Pearson's correlation coefficient.

$$
r=\frac{\sum(x-\bar{X})^{2} \sum(y-\bar{Y})^{2}}{\sqrt{\sum(x-\bar{X})^{2} \sum(y-\bar{Y})^{2}}}=-0.31
$$

$\Sigma$ is summation of where

" $x$ " is MBAg and

" $y$ " is GDPg

$n(x)=28, n(y)=28$.

With a negative correlation between $x$ and $y$ we reject the NULL $\left(\mathrm{H}_{\mathrm{o}}\right)$.

\subsection{Chow Test of Stability}

First documented in 1960 the Chow test (Equation (2)) compares data sets to determine if two regressions explain the data with greater efficiency than one regression. If two regressions, in this case $S_{1}$ and $S_{2}$ are structurally different, the Chow test will fail (Table 3). In this case, the Chow test finds the Eisenhower-Carter economies are structurally different than the Reagan-Bush II economies.

\subsection{Equation (2)}

Chow test for stability
Table 3. Chow test for stability-95\% confidence.

\begin{tabular}{cccc}
\hline \multirow{3}{*}{$\begin{array}{c}\text { Score } \\
4.962\end{array}$} & & & \\
\cline { 2 - 4 } & C.V. & P-value & Stable \\
\hline & 4.020 & $3.01 \%$ & false \\
\hline
\end{tabular}

$$
\frac{\left(S_{c}-\left(S_{1}+S_{2}\right)\right) /(k)}{\left(S_{1}+S_{2}\right) /\left(N_{1}+N_{2}-2 k\right)}=4.962
$$

where " $S_{1}$ " is 1953-1980 GDPg and " $S_{2}$ " is 1981-2008 GDPg $N=$ observation count $\left(N_{1}+N_{2}-2 k\right)=$ degrees of freedom

\section{Conclusions}

Statistics of estimation do not predict as much as they describe. There appears to be no empirical evidence in this study to suggest the rising management preference for the MBA since 1980 has improved US economic performance. There is evidence that the MBA is associated with $31 \%$ of the decline in GDPg after 1980. Moreover, the US Economy has been structurally altered when comparing the better performing Eisenhower-Carter economies (1953-1980) with Reagan-Bush II economies (19812008).

Could it be the preference for MBA degreed management of public and private organizations since 1980 has changed the US economic structure and restricted economic growth? This notion can not be rejected. Future work in this field may want to look at the role public budgets play in economic growth, public private investment ratios and tax policy. 


\section{REFERENCES}

[1] D. T. Campbell and E. S. Overman, "Methodology and Epistemology for Social Science: Selected Papers," University of Chicago Press, Chicago, 1988.

[2] National Center for Educational Statistics (NCES), "Percentage of Persons Age 25 and over and 25 to 29, by Race/Ethnicity, Years of School Completed, and Sex: Selected Years, 1910 through 2010," US Digest of Educational Statistics, 2011. http://nces.ed.gov/programs/digest/d10/tables/dt10_008.a $\mathrm{sp}$

[3] J. S. Landefeld, E. P. Seskin and B. M. Fraumeni, "Taking the Pulse of the Economy: Measuring GDP," Journal of Economic Perspectives, Vol. 22, No. 2, 2008, pp. 193216.

[4] Bureau of Economic Assessment (BEA), National Economic Accounts: "Current-dollar and 'real' GDP," US Department of Commerce, 2013. http://www.bea.gov/national/index.htm
[5] National Center for Educational Statistics, "Percentage of Persons Age 25 and over and 25 to 29, by Race/Ethnicity, Years of School Completed, and Sex: Selected Years, 1910 through 2010," US Digest of Educational Statistics, 2011.

http://nces.ed.gov/programs/digest/d10/tables/dt10_008.a $\mathrm{sp}$

[6] M. Murray, "MBA Share in the U.S. Graduate Management Education Market," Business Education \& Administration, Vol. 3, No. 1, 2012, pp. 29-40.

[7] "Note: Mental Models Are Deeply In-Grained Assumptions, Generalizations, or Even Pictures of Images That Influence How We Understand the World and How We Take Action," 5th Discipline, Double Day, New York, London, Toronto, Sydney, Auckland, 1990, 2006.

[8] ibid NCES.

[9] ibid NCES.

[10] ibid NCES.

[11] ibid BEA.

\section{Abbreviations and Acronyms}

GDP: Gross Domestic Product

MBA: Masters of Business Administration GDPg: GDP Growth
MBAg: MBA growth

BEA: US Bureau of Economic Assessment NCES: National Center for Educational Statistics 